Int. J. Electrochem. Sci., 15 (2020) $6769-6777$

International Journal of

ELECTROCHEMICAL

SCIENCE

WWW.electrochemsci.org

\title{
The Significant Effect of Supporting Electrolytes on the Galvanic Deposition of Metallic Rhenium
}

\author{
Huazhen Cao, Lilong Hu, Huibin Zhang, Guangya Hou, Yiping Tang, Guoqu Zheng* \\ College of Materials Science and Engineering, Zhejiang University of Technology, Hangzhou, 310014, \\ China \\ *E-mail: zhenggq@zjut.edu.cn
}

doi: $10.20964 / 2020.07 .53$

Received: 1 March 2020 / Accepted: 29 April 2020 / Published: 10 June 2020

The effects of a supporting electrolyte $\left(\mathrm{Na}_{2} \mathrm{SO}_{4}\right)$ on the galvanic deposition of metallic rhenium from acidic ammonium perrhenate aqueous solution were investigated. The results show that the supporting electrolyte plays an important role in the galvanic deposition of metallic rhenium. The main product in the more concentrated $\mathrm{NH}_{4} \mathrm{ReO}_{4}$ solution is only rhenium oxides in the absence of supporting electrolyte due to substantial hydrogen evolution reaction (HER). However, the introduction of a supporting electrolyte enhances the activation energy of the HER, resulting in the formation of metallic rhenium. The current efficiency is as high as $31.4 \%$ under optimized conditions, which is far above the values previously reported.

Keywords: metallic rhenium; electrodeposition; supporting electrolyte; sodium sulfate

\section{$\underline{\text { FULL TEXT }}$}

(C) 2020 The Authors. Published by ESG (www.electrochemsci.org). This article is an open access article distributed under the terms and conditions of the Creative Commons Attribution license (http://creativecommons.org/licenses/by/4.0/). 